ORIGINAL ARTICLE

\title{
Participation in leanness sports but not training volume is associated with menstrual dysfunction: a national survey of 1276 elite athletes and controls
}

\author{
M K Torstveit, J Sundgot-Borgen
}

Br J Sports Med 2005;39:141-147. doi: 10.1136/bjsm.2003.011338

See end of article for authors' affiliations

Correspondence to:

Mrs Torstveit, Norwegian

University of Sport and PE,

PO Box 4014, Ullevaal

Stadion, Oslo 0806,

Norway; monica.

torstveit@nih.no

Accepted 6 April 2004

\begin{abstract}
Objective: To examine the prevalence of menstrual dysfunction in the total population of Norwegian elite female athletes and national representative controls in the same age group.

Methods: A detailed questionnaire that included questions on training and/or physical activity patterns, menstrual, dietary, and weight history, oral contraceptive use, and eating disorder inventory subtests was administered to all elite female athletes representing the country at the junior or senior level (aged 13-39 years, $n=938)$ and national representative controls in the same age group $(n=900)$. After exclusion, a total of 669 athletes $(88.3 \%)$ and 607 controls $(70.2 \%)$ completed the questionnaire satisfactorily.

Results: Age at menarche was significantly $(p<0.001)$ later in athletes (13.4 (1.4) years) than in controls (13.0 (1.3) years), and differed among sport groups. A higher percentage of athletes (7.3\%) than controls $(2.0 \%)$ reported a history of primary amenorrhoea $(p<0.001)$. A similar percentage of athletes $(16.5 \%)$ and controls (15.2\%) reported present menstrual dysfunction, but a higher percentage of athletes competing in leanness sports reported present menstrual dysfunction $(24.8 \%)$ than athletes competing in non-leanness sports $(13.1 \%)(p<0.01)$ and controls $(p<0.05)$.

Conclusions: These novel data include virtually all eligible elite athletes, and thus substantially extend previous studies. Age at menarche occurred later and the prevalence of primary amenorrhoea was higher in elite athletes than in controls. A higher percentage of athletes competing in sports that emphasise thinness and/or a specific weight reported present menstrual dysfunction than athletes competing in sports focusing less on such factors and controls. On the basis of a comparison with a previous study, the prevalence of menstrual dysfunction was lower in 2003 than in 1993.
\end{abstract}

n the late 1970s, an association between exercise and menstrual problems, such as delayed menarche or secondary amenorrhoea, was suggested. ${ }^{1}$ By the 1980s, the association between exercise and amenorrhoea was well recognised, ${ }^{2}$ and, by the end of the 1990s, it was claimed that a significant number of female athletes were at risk of disturbed menstrual function. ${ }^{3}$ Exercise, low body weight, inadequate energy availability, and psychological stress are being investigated as potential causes of disruption of the normal endocrine process. ${ }^{45}$ However, most data to date suggest that energy availability is the main cause of exercise associated amenorrhoea. ${ }^{67}$

Primary amenorrhoea, or delayed menarche, is the absence of menstruation by age 16 in a girl with secondary sex characteristics. ${ }^{3}$ It has been observed that the menarcheal age in athletes competing in activities that demand very low weight, such as ballet dancing, gymnastics, and figure skating, is significantly later than that of non-athletes. ${ }^{8}$

Furthermore, it has been reported that delayed menarche, primary and secondary amenorrhoea, and oligomenorrhoea occur in $6-79 \%$ of women engaged in athletic activity. ${ }^{8}$ Otis ${ }^{9}$ claims that the estimated prevalence of secondary amenorrhoea is $3-66 \%$ in athletes compared with $2-5 \%$ in the general population. The wide range observed in athletes may be explained by a number of methodological factors that vary, such as: the definition of menstrual dysfunction (MD); the competition level of the athletes; and the sport discipline, which may vary in intensity and frequency of training. In addition, these studies were published from one to four decades ago. Over the last 10 years, few studies have investigated the prevalence of $\mathrm{MD}$ in high level athletes and controls, ${ }^{10-13}$ and only one previous study, published
10 years ago, has reported the prevalence of MD in a total population of elite athletes compared with age matched controls. ${ }^{14}$ Because MD may have a profound negative effect on skeletal development, ${ }^{35^{16}}$ it is important to discover the present prevalence of these endocrine abnormalities in female populations to facilitate effective treatment and preventive intervention. Thus, the aim of this study was to examine the prevalence of MD in the total population of Norwegian elite female athletes and national representative non-athletic controls.

\section{METHODS}

Subjects

The total population of elite female athletes in Norway, aged 13-39 years ( $\mathrm{n}=938)$, and non-athletic controls in the same age group $(n=900)$ were invited to participate in the study. Permission to undertake the study was provided by the Norwegian Olympic Committee and the Norwegian Confederation of Sports, the Data Inspectorate and the Regional Committee for Medical Research Ethics. The secretary general of each sport federation and the head of the healthcare team for each of the national teams received detailed written information about the procedures and aims of the study. In addition, all secretary generals were asked to return a list containing names, ages, and addresses of all eligible athletes in their federation competing for national teams. All participants received an information letter and had

Abbreviations: BMI, body mass index; EDI, eating disorder inventory; HPA, history of primary amenorrhoea; HSA, history of secondary amenorrhoea; $M D$, menstrual dysfunction; $M D-O C$, menstrual dysfunction-oral contraceptive; PMD, present menstrual dysfunction 


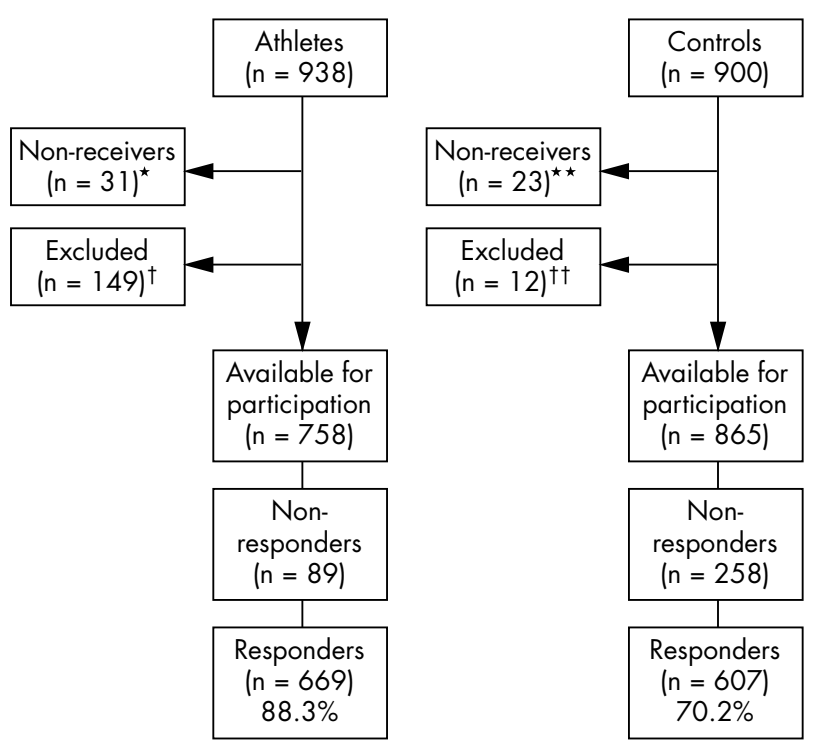

Figure 1 Flow chart showing selection of athlete and control samples based on questionnaire mailing, exclusion process, and questionnaire response. *Because they were representing teams in other countries or were travelling. **Because of problems finding their addresses. †Seventy six athletes had ended their career, 35 did not compete at the national level, 15 were injured, eight were pregnant and did not plan to continue their athletic career after the delivery, five were older than 39 years of age, nine did not complete the questionnaire satisfactorily, and one athlete competed in two different sport groups. ††Nine did not understand the Norwegian language, and three were severely ill and were unable to fill in the questionnaire.

to complete a written consent form. Parents of responders younger than 18 years old had the opportunity to refuse participation on behalf of their child, and written parental consent was required for responders younger than 16 .

We defined an elite athlete as one who qualified for the national team at the junior or senior level, or who was a member of a recruiting squad for that team. The athletes had to be 13-39 years old. Exclusion criteria included: pregnancy with a subsequent plan to discontinue the athletic career after delivery; severe injury which had prevented the athlete from training for more than three months; participation in two different sport groups.

The athletes represented 66 different sports/events. For parts of the analysis, these sports/events were divided into different sport groups: technical $\left(G_{1}\right)$, endurance $\left(G_{2}\right)$, aesthetic $\left(G_{3}\right)$, weight class $\left(G_{4}\right)$, ball game $\left(G_{5}\right)$, power
$\left(G_{6}\right)$, and anti-gravitation $\left(G_{7}\right)$ sports. ${ }^{14}{ }^{17}$ Furthermore, for parts of the analysis and in accordance with previous research, ${ }^{18}$ the seven different sport groups were divided into leanness sports $\left(G_{2}, G_{3}, G_{4}\right.$ and $\left.G_{7}\right)$ and non-leanness sports $\left(G_{1}, G_{5}\right.$ and $\left.G_{6}\right)$.

A bureau of statistics picked a randomly selected sample of controls $(\mathrm{n}=900)$ from the whole female population of Norway aged 13-39 years. Every county was represented, and an approximate identical percentage age and geographical distribution in relation to the total population was calculated. Exclusion criteria included severe illness and unfamiliarity with the Norwegian language, which would lead to problems answering the questionnaire.

\section{Assessment procedures}

A questionnaire including a battery of assessment questions was sent to each of the 938 eligible athletes and 900 eligible controls. Figure 1 shows a flow chart of questionnaire mailing and response. None of the controls competed in sports for a national team, and thus they were classified as non-athletic controls.

In addition to questions on menstrual history, oral contraceptive use, and pregnancy, subtests of the eating disorder inventory (EDI) ${ }^{14} 1920$ and questions on weight history, training history, training time and physical activity patterns, dietary history, nutritional habits, possible eating disorders, and injury history were included.

\section{Menstrual dysfunction (MD)}

Eumenorrhoea can be defined as regular menstrual cycles ranging from 26 to 32 days. ${ }^{21}$ In this study, primary amenorrhoea was defined as the absence of menarche by the age of 16, and secondary amenorrhoea as the absence of three or more consecutive menstrual cycles after menarche and outside pregnancy. Furthermore, we defined oligomenorrhoea as menstrual cycles of 35 days or more, and short luteal phase as a menstrual cycle of less than 22 days. Primary amenorrhoea, secondary amenorrhoea, oligomenorrhoea, and short luteal phase were all defined as MD. If present primary amenorrhoea, secondary amenorrhoea, oligomenorrhoea, or short luteal phase were reported, the subject was diagnosed with present menstrual dysfunction (PMD). In addition, a lifetime prevalence of primary and secondary amenorrhoea was reported, and in this study described as a history of primary amenorrhoea (HPA) or secondary amenorrhoea (HSA).

The oral contraceptive users $(269$ athletes and 167 controls) and those younger than 16 years (59 athletes and 61 controls) were excluded from the analyses related to PMD.

Table 1 Anthropometric data presented for each sport group and controls

\begin{tabular}{|c|c|c|c|c|c|c|}
\hline & $\mathbf{N}$ & Age (years) & Weight (kg) & Height $(\mathrm{cm})$ & BMI $\left(\mathrm{kg} / \mathrm{m}^{2}\right)$ & $\begin{array}{l}\text { Age at menarche } \\
\text { (years) }\end{array}$ \\
\hline Technical $\left(G_{1}\right)^{*}$ & 90 & $22.5(5.7)$ & $64.6(9.2)$ & $169.5(5.5)$ & $22.4(2.8)$ & $13.3(1.6)$ \\
\hline Endurance $\left(G_{2}\right) \dagger$ & 113 & $22.3(6.3)$ & $58.4(6.4)^{a}$ & $168.6(5.6)$ & $20.5(1.8)^{b}$ & $13.8(1.5)^{\mathrm{c}}$ \\
\hline Aesthetic $\left(G_{3}\right) \dagger$ & 65 & $17.3(4.6)^{\mathrm{d}}$ & $51.5(7.4)^{\mathrm{e}}$ & $162.4(6.8)^{\mathrm{e}}$ & $19.5(2.0)^{f}$ & $14.0(1.4)^{\mathrm{g}}$ \\
\hline Weight class $\left(G_{4}\right) \dagger$ & 35 & $24.3(5.6)^{h}$ & $63.4(8.6)$ & $167.3(6.2)$ & $22.8(3.3)$ & $12.7(1.6)^{\mathrm{i}}$ \\
\hline Ball game $\left(G_{5}\right)^{*}$ & 308 & $21.0(4.6)$ & $64.4(7.8)$ & $170.8(6.5)^{k}$ & $22.0(2.0)$ & $13.3(1.4)$ \\
\hline Power $\left(G_{6}\right)^{*}$ & 40 & $21.5(3.8)$ & $62.9(5.8)$ & $168.9(5.0)$ & $22.1(2.0)$ & $13.9(1.6)$ \\
\hline Anti-gravitation $\left(G_{7}\right) \dagger$ & 18 & $21.4(5.4)$ & $58.3(7.3)^{i}$ & $168.9(6.7)$ & $20.4(1.5)^{i}$ & $13.3(1.2)$ \\
\hline All athletes & 669 & $21.3(5.3)^{k}$ & $61.8(8.7)^{\mathrm{k}}$ & $169.1(6.6)^{k}$ & $21.6(2.4)^{k}$ & $13.4(1.4)^{\mathrm{k}}$ \\
\hline Controls & 607 & $27.3(8.0)$ & $65.8(12.9)$ & $167.6(6.0)$ & $23.4(4.3)$ & $13.0(1.3)$ \\
\hline
\end{tabular}

Values are mean (SD).

*Non-leanness sports. †Leanness sports.

${ }^{a} p<0.001$ compared with $G_{1}, G_{5}$ and $G_{6}$ and $p=0.002$ compared with $G_{4} ;{ }^{b} p<0.001$ compared with $G_{1}, G_{4}, G_{5}$ and $G_{6} ;{ }^{c} p<0.001$ compared with $G_{4}$; ${ }^{d} p<0.001$ compared with all other sport groups; ${ }^{e} p<0.001$ compared with $G_{1}, G_{2}, G_{4}, G_{5}$ and $G_{6}$ and $p=0.002$ compared with $G_{7} ; p<0.001$ compared with $G_{1}, G_{4}, G_{5}$ and $G_{6}$ and $p=0.002$ compared with $G_{2} ;{ }^{g} p<0.001$ compared with $G_{4}$ and $G_{5}$ and $p=0.002$ compared with $G_{1} ; h^{h}<0.001$ compared with $G_{5}$; $i p<0.001$ compared with $G_{2}, G_{3}$ and $G_{6} ; i p<0.001$ compared with $G_{5} ;{ }^{k} p<0.001$ compared with controls. 
Table 2 Self reported history of primary amenorrhoea (HPA) and secondary amenorrhoea (HSA) in the different sport groups, in all athletes (ATH), and in controls (CON)

\begin{tabular}{llllllllll}
\hline & $G_{1}(n=84)$ & $G_{2}(n=104)$ & $G_{3}(n=32)$ & $G_{4}(n=35)$ & $G_{5}(n=302)$ & $G_{6}(n=40)$ & $G_{7}(n=17)$ & ATH $(n=614)$ & CON $(n=546)$ \\
\hline HPA & 1.2 & 10.6 & $21.9^{a}$ & 8.6 & 6.0 & 10.0 & 5.9 & $7.3^{b}$ & 2.0 \\
HSA & 16.7 & $30.9^{a}$ & 34.5 & 23.5 & 12.8 & 12.8 & 17.6 & $18.2^{c}$ & 13.5 \\
\hline
\end{tabular}

Data are given as valid percentage - that is, the percentage of cases having HPA/HSA when only cases without missing values are considered. Those younger than 16 were excluded.

${ }^{a} p<0.001$ compared with $G_{5} ;{ }^{b} p<0.001$ compared with controls (age and BMl adjusted); ${ }^{c} p<0.05$ compared with controls (not significant when adjusting for age and BMII).

Sport groups: $G_{1}$, technical; $G_{2}$, endurance; $G_{3}$, aesthetic; $G_{4}$, weight class; $G_{5}$, ball game; $G_{6}$, power; $G_{7}$, anti-gravitation.

However, subjects who reported that they used oral contraceptives to restore their menstrual cycle were identified as the menstrual dysfunction-oral contraceptive (MD-OC) group. When subjects with HPA or HSA were analysed, only those younger than 16 were excluded. For parts of the analysis, the participants were divided into three different age groups: 13$19,20-29$, and 30-39 years.

\section{Training volume}

Total training was defined as the total hours of training a week for the athletes (presented as a mean of the training and competition period during the previous year). Amount of physical activity among the controls was defined as the total hours of physical activity a week including physical education lessons, recreational sports, and active daily living like walking. This value was calculated on the basis of questions about type of physical activity, frequency, and duration during the previous year. For parts of the analysis, the athletes and controls were divided into quartiles based on their physical activity level.

\section{Statistical analysis}

All analyses were performed using SPSS software, version 11.0 (SPSS, Evanstron, Illinois, USA). Results are expressed as mean (SD) or $95 \%$ confidence interval (CI). Comparisons between athletes and controls, leanness and non-leanness sports, the different age groups, and the physical activity quartiles were carried out using two sample Student's $t$ test

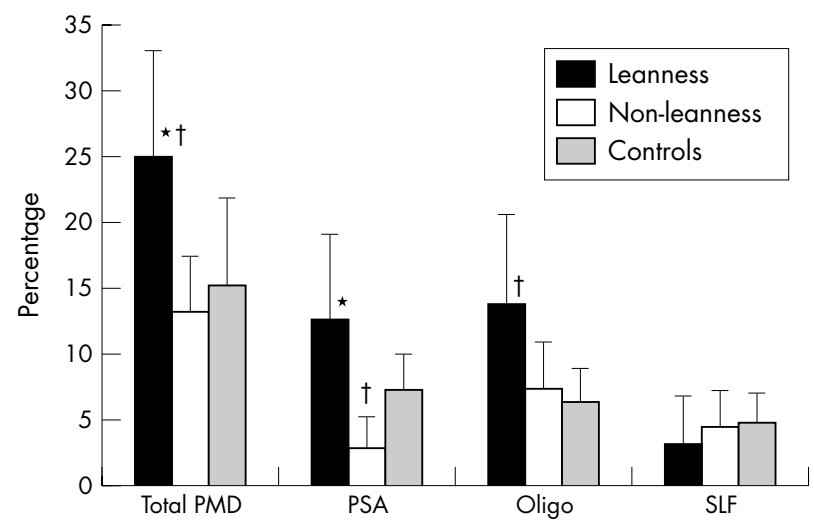

Figure 2 Percentage of athletes separated into leanness $(n=105)$ and non-leanness sports $(n=229)$ and controls $(n=375)$ reporting present menstrual dysfunction (PMD) (mean and 95\% confidence interval). Oral contraceptive users and those younger than 16 were excluded. PSA, Present secondary amenorrhoea; Oligo, oligomenorrhoea; SLF, short luteal phase. Each responder could report more than one type of $M D$, but was only counted as one in the PMD group. Therefore the percentage of secondary amenorrhoea, oligomenorrhoea, short luteal phase, and primary amenorrhoea ( $n=1$, not shown in the figure) is more than $100 \%$. ${ }^{*} p<0.01$ compared with non-leanness; $\uparrow p<0.05$ compared with controls. for continuous data, and $\chi^{2}$ test for categorical data. Fisher's exact test was carried out when the cells had expected counts of less than five. Differences were considered significant for $p$ values equal to or less than 5 . A power function analysis was conducted. Assuming the prevalence of PMD to be 15\%, the size of the study has a power of $90 \%$ to detect a difference in prevalence of PMD between athletes and controls of at least $7 \%$ at the 5\% significance level. Comparisons between the sport groups were carried out using non-parametric tests (Kruskal-Wallis test and Mann-Whitney test) for continuous data, and $\chi^{2}$ test for categorical data. All tests were two tailed. In order to prevent type I error, the Bonferroni method of adjustment was used when describing differences between the seven sports groups. For these multiple comparisons, the significance level was adjusted by dividing the conventional 0.05 level by the number of $t$ tests $(n=21)$ per variable. Seven groups were to be compared, two by two, and from combinatorial mathematics you have 7 over $2=21$ unordered comparisons. Therefore, the actual significance level for each of these multiple comparisons was equal to or less than 0.002 . Only significant differences at or below this level are shown in the results. Binary logistic regression analysis was carried out to investigate the relation between PMD and a set of risk factors, including adjustments for differences in age and body mass index (BMI) between athletes and controls.

\section{RESULTS}

\section{Subject characteristics}

The athletes were younger and reported lower BMI values than the controls $(\mathrm{p}<0.001)$. The BMI was still lower in athletes than in controls after adjustment for age $(\mathrm{p}<0.001)$. Athletes competing in aesthetic sports were younger, and had lower height and weight than all other sport groups $(\mathrm{p}<0.002)$ (table 1$)$.

No age difference between athletes competing in leanness sports and non-leanness sports was found (21.1 (6.2) years and 21.4 (4.8) years respectively). Athletes competing in leanness sports had a significantly $(\mathrm{p}<0.001)$ lower weight $(57.2(8.1) \mathrm{kg})$ and BMI $\left(20.5(2.4) \mathrm{kg} / \mathrm{m}^{2}\right)$ than those competing in non-leanness sports $(64.3(7.9) \mathrm{kg}$ and 22.1 (2.2) $\mathrm{kg} / \mathrm{m}^{2}$ ).

\section{Training volume}

The athletes trained on average 13.2 (5.2) hours a week. Athletes competing in aesthetic sports reported the highest training volume (16.7 (5.7) hours), followed by athletes competing in power (14.7 (4.4) hours), technical (14.5 (6.2) hours), weight class (14.0 (4.4) hours), endurance (13.0 (4.4) hours), anti-gravitation (12.9 (4.1) hours), and ball game (11.8 (4.7) hours) sports. The controls reported being physically active 5.3 (5.3) hours a week.

\section{Oral contraceptives}

A higher percentage of athletes (40.2\%) than controls $(27.5 \%)$ reported present use of oral contraceptives 
Table 3 Present menstrual dysfunction in athletes in different sport groups, in all athletes, and in controls (CON)

\begin{tabular}{lllllllll}
\hline$G_{1}(n=52)$ & $G_{2}(n=59)$ & $G_{3}(n=20)$ & $G_{4}(n=17)$ & $G_{5}(n=158)$ & $G_{6}(n=19)$ & $G_{7}(n=9)$ & ATH $(n=334)$ & $\operatorname{CON}(n=375)$ \\
\hline $7(13.5)$ & $18(30.5)$ & $6(30.0)$ & $1(5.9)$ & $20(12.7)$ & $3(15.8)$ & $1(11.1)$ & $55(16.5)$ & $57(15.2)$ \\
\hline
\end{tabular}

Data are given as numbers (\%). Oral contraceptive users and those younger than 16 were excluded.

Sport groups: $G_{1}$, technical; $G_{2}$, endurance; $G_{3}$, aesthetic; $G_{4}$, weight class; $G_{5}$, ball game; $G_{6}$, power; $G_{7}$, anti-gravitation.

$(\mathrm{p}<0.001)$. The difference was still significant $(\mathrm{p}<0.001)$ after adjustment for age and BMI. Twenty one percent $(\mathrm{n}=57)$ and $18 \%(\mathrm{n}=30)$ of these athletes and controls respectively reported that they used oral contraceptives to restore their menstrual cycle (MD-OC group). There were no significant differences between the MD-OC groups, nor after adjustment for age and BMI. A higher percentage of controls $(64.2 \%)$ than athletes $(32.8 \%)$ reported previous use of oral contraceptives $(p<0.001)$. This difference was, however, not significant after adjustment for age and BMI.

\section{Age at menarche}

Age at menarche occurred later in athletes (13.4 (1.4) years) than in controls ( $13.0(1.3)$ years $)(\mathrm{p}<0.001)$, and differed among the sport groups (table 1). Athletes competing in leanness sports reported a later age at menarche (13.7 (1.5) years) than athletes competing in non-leanness sports (13.3 (1.4) years) $(\mathrm{p}<0.01)$.

Forty two percent of the athletes started sport specific training before reaching menarche, and this group reached menarche significantly later (13.9 (1.4) years) than those who started sport specific training after menarche (13.1 (1.4) years) $(\mathrm{p}<0.001)$.

\section{Menstrual dysfunction (MD)}

One athlete representing the aesthetic sport group and no controls reported present primary amenorrhoea. Table 2 shows the prevalence of HPA and HSA.

A higher percentage of athletes competing in leanness sports $(11.7 \%)$ reported HPA than athletes competing in nonleanness sports $(5.4 \%) \quad(\mathrm{p}<0.01)$ and controls $(2.0 \%)$ $(\mathrm{p}<0.001)$. Also, more athletes competing in non-leanness sports than controls reported HPA $(\mathrm{p}<0.01)$. Furthermore, a higher percentage of athletes competing in leanness sports $(28.7 \%)$ than athletes competing in non-leanness sports $(13.6 \%)$ and controls $(\mathrm{p}<0.001)$ reported HSA. No difference was, however, found between athletes competing in nonleanness sports and controls.

A similar percentage of athletes (16.5\%) and controls (15.2\%) reported PMD (table 3 ). No difference in PMD was found after adjustment for age and BMI. No significant differences were observed between athletes and controls in the prevalence of present secondary amenorrhoea, oligomenorrhoea, or short luteal phase, per se nor after adjustment for age and BMI. However, when the athletes were divided up according to leanness and non-leanness sports, a higher percentage of athletes competing in leanness sports than controls reported PMD and oligomenorrhoea. A higher percentage of controls than athletes competing in nonleanness sports reported present secondary amenorrhoea (fig 2). Furthermore, when the percentage of athletes competing in leanness sports were compared with those reporting MD-OC competing in non-leanness sports (11.2\% and $9.0 \%$ respectively), no differences were found. The highest percentage of PMD was reported by athletes competing in aesthetic sports and endurance sports (table 3 ).

When physical activity level was divided into quartiles in the control group, no differences in any of the four definitions of PMD were found between the four activity groups. Furthermore, when the control group was divided into two groups on the basis of their physical activity level (highest quartile compared with the three lower quartiles), no significant differences in any of the four definitions of PMD were found (data not shown). The athletes were also divided into quartiles on the basis of total training volume. No significant differences in the different PMDs were found between the quartiles or between the highest quartile and the three lower quartiles (data not shown).

No significant differences in PMD between the three age groups (16-19, 20-29, and 30-39 years) were found in the athletic or control group, nor when athletes and controls in the different age groups were compared.

Age, menarcheal age, BMI, EDI-body dissatisfaction (BD) score, and nulliparity contributed significantly to explaining PMD in athletes $(20.9 \%)$. Training volume, smoking, and EDI-drive for thinness (DT) score were not associated with PMD in athletes. In controls, menarcheal age contributed significantly to explaining PMD (12.3\%). Amount of physical activity ( $\mathrm{p}=0.08$ ), age, smoking, EDI-DT and EDI-BD score, BMI, and nulliparity were not associated with PMD in controls.

\section{DISCUSSION}

\section{Age at menarche and primary amenorrhoea}

In accordance with previous studies, ${ }^{822} 23$ athletes in this study had a higher mean age at menarche than controls. Mean menarcheal age in the athletes was close to mean menarcheal age reported in previous studies. ${ }^{1422} 2425$ On the other hand, a later menarcheal age in athletes has been reported..$^{26}{ }^{27}$ Hata and Aoki ${ }^{28}$ showed that an increase in age at menarche was related to the competition level of the athletes: 12.6 (1.1), 12.9 (1.2), and 13.5 (1.3) years for high school, college, and top level athletes respectively. Thus, our results on elite athletes are in accordance with results for Japanese top level athletes.

In this study, more athletes (7\%) than controls $(2 \%)$ reported HPA. These results are in accordance with findings from a study on Croatian athletes reporting the prevalence of primary amenorrhoea to be higher in athletes $(8.3 \%)$ than in controls $(\mathrm{n}=0) .{ }^{11}$ We found the highest prevalence among athletes competing in aesthetic sports $(21.9 \%)$, endurance sports $(10.6 \%)$, and power sports $(10.0 \%)$. Few studies have investigated the prevalence of primary amenorrhoea in different sport groups; however, the highest prevalence has been detected in ballet dancers, runners, and swimmers. ${ }^{11} 29$

Menarcheal age is strongly genetically determined, ${ }^{30}{ }^{31}$ but the causes of primary amenorrhoea are complex and not completely understood. ${ }^{32}$ In accordance with a study on Croatian athletes, ${ }^{11}$ results from our study showed that athletes who started sport specific training before menarche experienced a significantly later age at menarche than those who started sport specific training after menarche. However, it is still not clear whether athletes have delayed menarche because of genetic factors, high training volume, or the possibility that their body type allows them to excel at sports and therefore would experience late menarche whether or not they were participating in sports. Prospective studies are needed to answer this question. 


\section{Menstrual dysfunction (MD)}

In contrast with other studies, ${ }^{10-12} 1433$ results from this study show that the same percentage of athletes and controls reported PMD and HSA (adjusted for age). However, on separation of the athletes into two groups, we did find that a higher percentage of those competing in leanness sports than controls reported PMD and HSA. In addition, more controls than athletes competing in non-leanness sports reported present secondary amenorrhoea. This may indicate that competing in sports focusing on leanness and/or a specific weight, but not in other sports, increases the risk of MD, and that normal active women in the Norwegian general population may be at the same risk as elite athletes competing in non-leanness sports with regard to developing MD. In accordance with our results, a previous study on elite athletes showed that the prevalence of MD was higher among athletes competing in leanness sports than among athletes competing in non-leanness sports. ${ }^{14}$

The high prevalence of MD may be explained by psychological stress or genetic factors. ${ }^{8}$ It has been claimed that amenorrhoea is caused by the woman's psychological preoccupation with weight and thinness which in turn may lead to weight loss. ${ }^{3}$ Also, to optimise performance, some athletes diet, use pathogenic weight control methods, and subsequently suffer from energy deficiency. Recent research suggests that lack of energy may be the main cause of $\mathrm{MD},{ }^{4} 6$ and this may explain the highest prevalence of MD being in athletes competing in leanness sports in this study.

The reasons for the lack of difference in prevalence of MD between athletes competing in non-leanness sports and the controls are uncertain. The prevalence of MD in the nonleanness group may be normal possibly because they do not have an energy deficit. If that is the case, then it would seem natural that athletes competing in non-leanness sports and non-athletic controls have the same prevalence of MD. On the other hand, it should be noted that the definition of short luteal phase used in this study may underestimate the true prevalence of short luteal phase, because short luteal phases occur in menstrual cycles of normal length as well as in short cycles. ${ }^{34}$ When it comes to athletes, De Souza et $a l^{34}$ found the three month incidence of luteal suppression to be $79 \%$ in regularly menstruating athletes whose cycles were normal in length. It is possible that the athletes in this study suffer from a higher prevalence of short luteal phase than the controls, but this difference is not shown using our definition.

In another Norwegian study, ${ }^{14}$ menarcheal age, training volume, BMI, and EDI score contributed significantly to explaining $\mathrm{MD}$ in elite athletes. In this study, menarcheal age, BMI, and EDI-BD score, in addition to nulliparity and age contributed to explaining PMD in athletes. The amount of physical activity did not contribute significantly $(\mathrm{p}=$ 0.08 ) to explaining PMD in the control group. The controls reported being physically active 5.3 (5.3) hours a week, including physical education lessons, recreational sports, and active daily living activities like walking. The high standard deviation indicates that a high percentage of the controls have a high activity level. Recent research suggests that exercise has no suppressive effect on the reproductive system except the energy cost of exercise leading to energy deficiency, ${ }^{4}$ which may be the case in the most active controls in our study.

Looking into the different sport groups, athletes competing in aesthetic and endurance sports reported the highest prevalence of PMD and HSA. The athletes competing in aesthetic sports were younger and had a lower weight than all the other sport groups. Furthermore, previous studies have shown that elite Norwegian athletes competing in aesthetic sports exhibit the highest prevalence of eating disorders and energy deficit, ${ }^{13}$ and this could be possible explanations for the high prevalence of $\mathrm{MD}$ in this sport group in our study.

There is a lack of studies comparable to ours including a comprehensive elite athlete survey and the strength of a random control group. Other studies have investigated the prevalence of MD among athletes competing in different sports, but they have not included a control group and/or have defined MD differently, and it is therefore difficult to compare their results with our study. ${ }^{13}{ }^{33} 35-37$

\section{Trends in the prevalence of MD over the last decade}

To our knowledge, only one published study ${ }^{14}$ is comparable to ours with regard to the subjects, methods, and definitions of MD. When comparing the results, a reduction in the prevalence of reported MD was observed over a 10 year period (from $42 \%$ to $17 \%$ in athletes and from $28 \%$ to $15 \%$ in controls). It should be noted that the athletic groups in the study by Sundgot-Borgen \& Larsen from $1993^{14}$ are comparable to those in this study as they were selected using the same criteria. The control groups, however, differ as they were age and home community matched, and not a representative sample of the general population. This has to be taken into consideration when comparing the results for the two control groups.

The reasons for a decreased prevalence of MD in the elite athletes during the last decade are uncertain. Many courses, workshops, and talks have been arranged for athletes, trainers, leaders, and medical staff over the last 10 years. This work, aimed at increasing the knowledge of, and changing attitudes in order to prevent, the female athlete triad, may partly explain the decreased prevalence of MD in athletes. The fear of increased injury risk-that is, stress fractures and bone loss-associated with MD may have motivated athletes with irregular menstrual cycles to increase their energy intake and/or seek help at an earlier stage than athletes 10 years ago, thereby preventing MD.

Another explanation for the decreased prevalence of MD in elite athletes may be the increase in the prevalence of athletes using oral contraceptives $(40 \% v 28 \%) .{ }^{14}$ This may partially be explained by the fact that clinicians are more likely now to prescribe oral contraceptives to athletes with symptoms of MD to prevent bone loss and injuries. Furthermore, it should be noted that, of the athletes and controls using oral contraceptives, $21 \%$ and $18 \%$ respectively reported that they used them to regulate their menstrual cycle (MD-OC group). These subjects were excluded from parts of the analysis because of their use of oral contraceptives, so the actual number who experienced PMD may be higher than our results indicate, because of the possible masking effect of the oral contraceptives.

Skeletal demineralisation seems to be caused by both hypo-oestrogenism associated with amenorrhoea and low insulin-like growth factor I caused by low energy availability. ${ }^{5}$ Oral contraceptives may restore oestrogen concentrations, but they will not improve nutritional status. Therefore, they may not be sufficient treatment for PMD. Athletes taking oral contraceptives to regulate their menstrual cycle may also have to increase their energy intake; otherwise, they may still be at risk of low bone mass. Moreover, it should be pointed out that oral contraceptives may have a deleterious effect on bone. ${ }^{38-40}$ This needs to be further investigated.

In addition, more women today tend to use hormonal birth control methods other than oral contraceptive pills than a decade ago. In both the study by Sundgot-Borgen and Larsen $^{14}$ and the present study, participants were only asked about oral contraceptive use, and only the oral contraceptive pill users were excluded from the data analysis. As a consequence, some women who reported regular menstruation, but were using, for example, hormone injections as a 


\section{What is already known on this topic}

A considerable number of female athletes are at risk of disturbed menstrual function.

method of contraception, would not have been excluded from the data analysis.

Differences in age (19.4 (4.3) v 21.3 (5.3) years) and BMI values (20.8 (2.4) v $\left.21.6(2.4) \mathrm{kg} / \mathrm{m}^{2}\right)$ may also be factors in the reduction of MD prevalence in athletes from $1993^{14}$ to 2003. The difference in mean BMI was not conspicuously large. However, the percentage of athletes with low BMI values $\left(<18.5 \mathrm{~kg} / \mathrm{m}^{2}\right)$ was higher in 1993 than in the present study (data not shown), and the athletes in the 1993 study were somewhat younger, and a higher percentage had started sport specific training at a young age than the athletes in the present study. There was no difference in training volume between the athletes in the two studies.

When it comes to the non-athletic controls, one can speculate whether the decrease in MD over the last decade is due to the same factors as for the athletes. However, the same percentage of controls used oral contraceptives in the two studies, and mean BMI in the controls was $21.7(2.9) \mathrm{kg} / \mathrm{m}^{2}$ and $23.4(4.3) \mathrm{kg} / \mathrm{m}^{2}$ in 1993 and 2003 respectively. This is a somewhat larger difference than among the athletes, but not necessarily of relevance. Physical activity level was almost identical in the two groups. A lower activity level was reported in the sample in 1993, but this is possibly because physical education lessons and active daily living activities such as walking were not included. In contrast, the higher actual and gynaecological age in the present study may explain the decreased prevalence in the control groups. A higher mean age may result in an increased probability of a stable menstrual cycle and the possibility of increased numbers of pregnancies, and thus lower prevalence of MD.

\section{Limitations}

We would like to point out some potential limitations of this study. Firstly, the design is retrospective, which may lead to problems of accurate recall of data on menarcheal age and the menstrual cycle in the past. The main results of this study, however, include present menstrual dysfunction, and questions about the present state should be more valid. Secondly, we chose to survey women in the same age range as the athletes, without matching for age. Unfortunately, the controls turned out to be older than the athletes. We have, however, applied appropriate statistical methods to adjust for this difference. Thirdly, despite the fact that our definitions of $\mathrm{MD}$ are in accordance with other comparable studies, some of the definitions related to MD are debatable. As we wanted to include not only amenorrhoea but also short luteal phase, the actual number with short luteal phase and consequently MD may have been underestimated as the result of the study design. Daily hormonal measurements of luteinising hormone and progesterone in the blood or urine for multiple consecutive menstrual cycles has been reported to be the best way to diagnose short luteal phase. ${ }^{34}$ This was not possible in this study. Finally, according to recent published studies on MD and energy deficit, it would have been advantageous if we had also investigated energy balance in both athletes and controls. However, this was not possible in this part of the study.

We believe that the results are generalisable to populations of elite athletes in other countries, but the results for the controls may not apply outside of Scandinavia because of the relatively high level of physical activity in this region.
What this study adds

Athletes in "leanness" sports have a higher prevalence of menstrual dysfunction than those in "non-leanness" sports and non-athletic controls. Furthermore, the prevalence is lower in both elite athletes and non-athletic premenopausal women compared with a decade ago.

\section{CONCLUSIONS}

This study shows that age at menarche is later in elite athletes than in controls and later in athletes who started sport specific training before menarche than for those who began after menarche. The difference in prevalence of MD between elite athletes and controls is not as large as previously assumed, and, in addition, the prevalence of MD is lower in both athletes and controls compared with one decade ago. However, a higher percentage of athletes competing in sports in which thinness and/or a specific weight is emphasised reported MD compared with athletes competing in sports focusing less on such factors and controls. We believe that MD prevention should not only be aimed at athletes in general, and especially athletes competing in leanness sports, but also at women in the general population.

\section{ACKNOWLEDGEMENTS}

This study was supported by research grants from The Norwegian Olympic Committee and Confederation of Sport, and The Norwegian Foundation for Health and Rehabilitation. We thank Professor Anne Loucks, and Associate Professor Sissel Tomten for their useful comments on the manuscript. We also acknowledge Professor Ingar Holme for statistical advice, Jennifer Arnesen for English revision of the manuscript, and Olov Belander, Elin Kolle, and Katrine M Owe for collecting data.

\section{Authors' affiliations}

M K Torstveit, J Sundgot-Borgen, Department of Sports Medicine, Norwegian University of Sport and PE, Oslo, Norway

Competing interests: none declared

\section{REFERENCES}

1 Malina RM, Spirduso WW, Tate C, et al. Age at menarche and selected menstrual characteristics in athletes at different competitive levels and in different sports. Med Sci Sports 1978;10:218-22.

2 Loucks AB, Horvath SM. Athletic amenorrhea: a review. Med Sci Sports Exerc 1985; 17:56-72.

3 Otis CL, Drinkwater B, Johnson M, et al. American college of sports medicine position stand. The female athlete triad. Med Sci Sports Exerc. 1997;29: i-ix).

4 Loucks AB. Energy availability, not body fatness, regulates reproductive function in women. Exerc Sport Sci Rev 2003:31:144-8.

5 Warren MP, Perlroth NE. The effects of intense exercise on the female reproductive system. J Endocrinol 2001;170:3-11.

6 Williams NI, Helmreich DL, Parfitt DB, et al. Evidence for a causal role of low energy availability in the induction of menstrual cycle disturbances during strenuous exercise training. J Clin Endocrinol Metab 2001;86:5184-93.

7 Loucks $A B$, Verdun $M$, Heath EM. Low energy availability, not stress of exercise, alters LH pulsatility in exercising women. J Appl Physiol 1998:84:37-46.

8 Constantini NW, Warren MP. Special problems of the female athlete. Baillieres Clin Rheumatol 1994;8:199-219.

9 Otis CL. Exercise-associated amenorrhea. Clin Sports Med 1992;11:351-62.

10 Constantini NW, Warren MP. Menstrual dysfunction in swimmers: a distinct entity. J Clin Endocrinol Metab 1995;80:2740-4.

11 Dusek T. Influence of high intensity training on menstrual cycle disorders in athletes. Croat Med J 2001;42:79-82.

12 Robinson TL, Snow-Harter C, Taaffe DR, et al. Gymnasts exhibit higher bone mass than runners despite similar prevalence of amenorrhea and oligomenorrhea. J Bone Miner Res 1995;10:26-35.

13 Sundgot-Borgen J. Eating disorders, energy intake, training volume, and menstrual function in high-level modern rhythmic gymnasts. Int I Sport Nutr 1996;6:100-9.

14 Sundgot-Borgen J, Larsen S. Preoccupation with weight and menstrual function in female elite athletes. Scand J Med Sci Sports 1993;3:156-63. 
15 Warren MP, Brooks-Gunn J, Hamilton $\mathrm{LH}$, et al. Scoliosis and fractures in young ballet dancers. Relation to delayed menarche and secondary amenorrhea. N Engl J Med 1986;314:1348-53.

16 Khan KM, Liu-Ambrose T, Sran MM, et al. New criteria for female athlete triad syndrome? As osteoporosis is rare, should osteopenia be among the criteria for defining the female athlete triad syndrome? Br J Sports Med 2002;36:10-13

17 Sundgot-Borgen J, Torstveit MK. Prevalence of eating disorders in elite athletes is higher than in the general population. Clin J Sport Med 2004; 14:25-32.

18 Sundgot-Borgen J. Prevalence of eating disorders in elite female athletes. Int J Sport Nutr 1993;3:29-40.

19 Garner DM, Olmsted MP, Polivy J. Manual of eating disorder inventory. Latz, FL: Odessa, 1984

20 Garner DM, Garfinkel PE, Rockert W, et al. A prospective study of eating disturbances in the ballet. Psychother Psychosom 1987;48:170-5.

21 Vollman RF. The menstrual cycle. In: Friedman EA, ed. Major problems in obstetrics and gynaecology. Philadelphia: WB Saunders Company, 1977.

22 Klentrou P, Plyley M. Onset of puberty, menstrual frequency, and body fat in elite rhythmic gymnasts compared with normal controls. $\mathrm{Br} J$ Sports Med 2003;37:490-4.

23 Malina RM. Menarche in athletes: a synthesis and hypothesis. Ann Hum Biol 1983;10:1-24

24 Cavanaugh DJ, Kanonchoff AD, Bartels RL. Menstrual irregularities in athletic women may be predictable based on pre-training menses. J Sports Med Phys Fitness 1989;29:163-9.

25 Farmosi I. Data concerning the menarche-age of Hungarian female athletes. J Sports Med Phys Fitness 1983;23:89-94.

26 Baxter-Jones AD, Helms P, Baines-Preece J, et al. Menarche in intensively trained gymnasts, swimmers and tennis players. Ann Hum Biol 1994;21:407-15.

27 Malina RM, Katzmarzyk PT, Bonci CM, et al. Family size and age at menarche in athletes. Med Sci Sports Exerc 1997;29:99-106.
28 Hata E, Aoki K. Age at menarche and selected menstrual characteristics in young Japanese athletes. Res Q Exerc Sport 1990;61:178-83.

29 Frisch RE, Gotz-Welbergen AV, McArthur JW, et al. Delayed menarche and amenorrhea of college athletes in relation to age of onset of training. JAMA 1981;246:1559-63.

30 Malina RM, Ryan RC, Bonci CM. Age at menarche in athletes and their mothers and sisters. Ann Hum Biol 1994;21:417-22.

31 Brooks-Gunn J, Warren MP. Mother-daughter differences in menarcheal age in adolescent girls attending national dance company schools and nondancers. Ann Hum Biol 1988; 15:35-43.

32 Timmreck LS, Reindollar RH. Contemporary issues in primary amenorrhea. Obstet Gynecol Clin North Am 2003;30:287-302.

33 Toriola AL. Survey of menstrual function in young Nigerian athletes. Int J Sports Med 1988;9:29-34.

34 De Souza MJ, Miller BE, Loucks $A B$, et al. High frequency of luteal phase deficiency and anovulation in recreational women runners: blunted elevation in follicle-stimulating hormone observed during luteal-follicular transition. J Clin Endocrinol Metab 1998;83:4220-32.

35 Beals KA, Manore MM. Disorders of the female athlete triad among collegiate athletes. Int J Sport Nutr Exerc Metab 2002;12:281-93.

36 Fogelholm M, Van Marken L, Ottenheijm R, et al. Amenorrhea in ballet dancers in the Netherlands. Med Sci Sports Exerc 1996;28:545-50.

37 Wolman RL, Harries MG. Menstrual abnormalities in elite athletes. Clin Sports Med 1989;1:95-100.

38 Bennell K, White S, Crossley K. The oral contraceptive pill: a revolution for sportswomen? Br J Sports Med 1999;33:231-8

39 Burr DB, Yoshikawa T, Teegarden D, et al. Exercise and oral contraceptive use suppress the normal age-related increase in bone mass and strength of the femoral neck in women 18-31 years of age. Bone 2000;27:855-63.

40 Weaver CM, Teegarden D, Lyle RM, et al. Impact of exercise on bone health and contraindication of oral contraceptive use in young women. Med Sci Sports Exerc 2001;33:873-80.

\section{Register now!}

10th European Forum on Quality Improvement in Health Care

13-15 April 2005, ExCel Conference Centre, London

For further information on how to register please go to:

http://www.quality.bmipg.com 